\title{
Isolation, Identification and Growth of some Soil Hyphomycetes and Yeast-Like Fungi which Utilize Aromatic Compounds Related to Lignin
}

\author{
By MOIRA E. K. HENDERSON \\ Department of Microbiology, Macaulay Institute for Soil Research, \\ Craigiebuckler, Aberdeen
}

(Received 8 March 1961)

\begin{abstract}
SUMMARY
Fungi were isolated from soil under several vegetational types by an enrichment technique with vanillin or $p$-hydroxybenzaldehyde as sole source of carbon. Although similar morphologically, the isolates obtained are classified in two separate groups, yeasts and hyphomycetes. A study was made of the growth in pure culture of representative species, namely, Pullularia pullulans, Margarinomyces heteromorpha and $\boldsymbol{M}$. mutabilis on several aromatic compounds related to lignin.
\end{abstract}

\section{INTRODUCTION}

In previous studies concerning the decomposition of lignin by soil fungi (Henderson \& Farmer, 1955) a number of isolates were obtained from soil by means of the dilution-plate method. Apart from incorporating tannic acid in the medium used, in the hope that lignin-decomposing fungi might be indicated by the production of a brown coloration round the colonies, no special selective methods were applied. Subsequent work (Henderson, 1960) showed that the coloration with tannic acid was not linked with an ability to utilize compounds related to lignin and to decompose them; a similar conclusion was reached recently by Ross (1960). In the present investigations a soil enrichment technique with vanillin or $p$-hydroxybenzaldehyde as substrate was used with the aim of isolating lignin-decomposing fungi, and a survey of vegetational types similar to those studied previously carried out. This paper describes the isolation and growth of a number of yeast-like fungi which can utilize compounds related to lignin and which were not encountered in the previous studies.

\section{METHODS}

Soil samples were obtained from a heath, Scots Pine forest (actively decomposing litter and humus layers), peat moss, garden and field. With the exception of the Scots Pine litter and humus samples, which were collected by means of sterilized forceps from the appropriate exposed layer, the samples were obtained by scraping a freshly exposed face, from a depth of $6 \frac{1}{2}$ in. to $\frac{1}{2}$ in. below the surface, with a sterilized scoop. The samples, three from each area, were immediately transferred to sterile jars and were thoroughly mixed before the removal of samples for the isolation of micro-organisms.

Isolation of fungi. Portions (2.5 g.) of the 'soil' samples were added to $50 \mathrm{ml}$. sterile water contained in a Waring micro-blender, which was run at top speed for 
$1 \mathrm{~min}$. Samples $(0.5 \mathrm{ml}$.) of the resulting suspensions were added to $20 \mathrm{ml}$. lots of Turfitt's medium (Turfitt, 1944) omitting cholesterol and $\mathrm{FeSO}_{4} \cdot \mathbf{7 \mathrm { H } _ { 2 }} \mathrm{O}$ and adding $0.01 \%(\mathrm{w} / \mathrm{v})$ vanillin or $p$-hydroxybenzaldehyde as carbon source. After incubation at $27^{\circ}$ for 7 days the flasks were shaken by hand for $1 \mathrm{~min}$. and $1 \mathrm{ml}$. from each culture flask was transferred to a replicate flask which was incubated for a further 7 days. After incubation the flasks were again shaken by hand for one minute and $1 \mathrm{ml}$. portions of the resulting suspensions were used for the preparation of dilutions at $1 / 1000,1 / 10,000$ and $1 / 100,000$. One $\mathrm{ml}$. from each dilution was added to each of two plates of Waksman's agar (Waksman, 1922) modified by the replacement of peptone by $\mathbf{0 . 2 5} \%(\mathrm{w} / \mathrm{v})\left(\mathrm{NH}_{4}\right)_{2} \mathrm{SO}_{4}$. The plates were incubated for 14 days at $27^{\circ}$ and representative organisms were isolated from them during this period. The isolates were maintained in culture on potato glucose agar.

Growth experiments. Suspensions for inoculation were obtained by growing the organisms on $50 \mathrm{ml}$. modified Czapek mineral salts $\left(\mathrm{NaNO}_{3}, \mathbf{1 . 5}\right.$ g.; $\mathrm{MgSO}_{4} .7 \mathrm{H}_{2} \mathrm{O}$, 0.25 g.; $\mathrm{KH}_{2} \mathrm{PO}_{4}, 0.5 \mathrm{~g}$.; $\mathrm{KCl}, 0.25$ g.; glucose, 5 g.; Bacto yeast extract (Difco Laboratories, Detroit, Michigan), 2.5 g.; water, $500 \mathrm{ml}$.) and incubating at $27^{\circ}$ for 2 days. The resulting growth was centrifuged off, washed three times with sterile water and suspended in $10 \mathrm{ml}$. water. One ml. portions of these suspensions were added to $99 \mathrm{ml}$. water and single drops, from a $1 \mathrm{ml}$. pipette, of the resulting suspensions served as inocula.

The basal mineral salts medium for the growth experiments was the same as that used above for the preparation of inocula, but with the glucose and yeast extract omitted. It was sterilized by autoclaving at $120^{\circ}$ for $20 \mathrm{~min}$. The required substrates, sterilized by filtration, were added to give final concentrations of $0.01 \%$ $(\mathrm{w} / \mathrm{v})$. Ten ml. lots of media were dispensed in $1 \mathrm{oz}$. vials closed with cotton-wool plugs. After inoculation the bottles were incubated on a shaking machine for 5 days at $27^{\circ}$.

Estimation of growth. In agitated liquid media the fungi grew in a predominantly unicellular form and growth was estimated by counting the number of viable organisms by the technique of Miles \& Misra (1938). Occasionally small pellets of mycelium were formed, which led to an abnormally low count. In order to obtain zero time counts, bottles containing $10 \mathrm{ml}$. water were inoculated in a similar way to the media. One ml. samples were removed aseptically immediately from such bottles and after 1, 2, 3, 4, and 5 days of incubation from the experimental bottles. These samples were used for the preparation of dilutions in the range $1 / 10$ to $1 / 10^{5}$, according to the amount of growth. The medium used for making the counts was potato glucose agar which, after pouring, was allowed to solidify and the plates, with the lids slightly raised, were then placed in an incubator at $60^{\circ}$ for $2 \mathrm{hr}$. to dry the surface of the agar. Three drops from each dilution were placed on plates which were then incubated at $27^{\circ}$ for 2 days (Pullularia pullulans, Margarinomyces mutabilis) or 3 days ( $M$. heteromorpha) before counting. The volume of the drops added to the plates being known, it was possible to calculate the number of organisms $/ \mathrm{ml}$. in the inocula and cultures. 


\section{RESULTS}

\section{Isolation of fungi by the enrichment technique}

The yield of organisms from the different areas varied markedly, there being in some cases a definite enrichment of fungi, while in others there was none. When enrichment did occur it was noticeable that most of the isolates obtained were similar morphologically. They were either mycelial yeasts or Fungi Imperfecti closely resembling these yeasts. These isolates were sent to the Centraalbureau voor Schimmelcultures, Baarn, Netherlands, for identification. A marked growth in the enrichment cultures was observed on incubating the Scots Pine litter sample in the presence of vanillin. Ten representative isolates were obtained in pure culture and were subsequently identified as Pullularia pullulans (6); Trichosporon cutaneum var. multisporum (1); Phialophora aurantiaca (1).

Two isolates (no. 8, 10) were not identical with any known species. Although not identical in all respects they were considered by the Baarn workers to belong to one species. The description of these two isolates was given as follows (personal communication):

'Elements, occurring in a young malt extract culture are very different in appearance: small cells round, about $1 \cdot 2-3 \mu$ in diameter, oval to long-oval cells $(2 \cdot 8-4 \cdot 5) \times$ (5-10) $\mu$. True mycelium, thinly septate, is produced. After 1 week a sediment is developed and a thin pellicle. The streak culture on malt agar after 1 week at room temperature is creamy and tough, hairy all over the surface in no. 8, in no. 10 hairy in the lower part, wrinkled in the upper part of the streak. In slide cultures on potato-agar outside the coverslip: good growth of true mycelium, the cross-walls of which are thin. Small round spores develop all along the mycelium, often on denticules. Under the coverslip a pseudomycelium develops as well, with oval or elongate blastospores. Asci and ascospores have not been found. These two strains do not ferment sugars. Aerobically glucose, galactose, saccharose, maltose and lactose are assimilated, the latter latently, in the auxanographic test. Ethanol is used as an only source of carbon in the liquid medium according to Wickerham; $\mathrm{KNO}_{3}$ is not utilized as an only source of nitrogen; external vitamins are required for development in a synthetic medium. There is no growth at $37^{\circ}$. Arbutin is split after 1 week at $25^{\circ}$. The "starch" reaction after 3 weeks of growth in a medium of low $\mathrm{pH}$ in shaking cultures was negative. Comparison of the assimilation of the two strains of thirty carbon sources in Wickerham's liquid medium resulted in differences only with sorbitol and erythritol.'

The heath soil sample also gave a definite enrichment when incubated in the presence of vanillin; six representative isolates were identified as Margarinomyces heteromorpha (2) and M. mutabilis (4). There was no enrichment from Scots Pine humus, while from peat moss a few colonies of Fusarium sp. were obtained when the samples were incubated with vanillin. Both vanillin and $p$-hydroxybenzaldehyde were used as substrates for the garden- and field-soil enrichments. No enrichment was obtained on either substrate from the field soil, but the garden soil gave an enrichment of fungi, one of which was identified as Geotrichum candidum and the description of the other (isolate no. 18), is as follows:

'On malt extract after 2 days at $25^{\circ}$ a white mouldy pellicle is formed. Microscopic examination shows elongate and cylindrical arthrospores, measuring 
(3-4) $\times(5-13) \mu$, and also true mycelium 3.5-5 $\mu$ in diameter. A young potato agar slide culture reveals true mycelium $2 \cdot 5-4.5 \mu$, and young "buds", arising on small projections, situated laterally on the mycelium, sometimes also on the joints of the arthrospores. Sometimes these "buds" are formed inside an empty cell of the mycelium. They contain an oildrop. There is no sign of development of ascospores. The organism is not capable of alcoholic sugar fermentation. Glucose and galactose are utilized as sources of carbon; sucrose, maltose, lactose and raffinose are not assimilated, neither is ethanol. $\mathrm{KNO}_{3}$ is not used as a sole source of nitrogen; arbutin is not split. The organism needs external vitamins for growth in a synthetic medium. It will not develop on malt agar at $37^{\circ}$.'

\section{Growth experiments}

The following isolates were used for growth experiments: Pullularia pullulans from Scots Pine litter; Margarinomyces heteromorpha and M. mutabilis, both from heath soil. Glucose was included as a substrate in all growth experiments, for

Table 1. Growth of Pullularia pullulans, Margarinomyces heteromorpha and M. mutabilis on aromatic substrates

Aromatic compounds or glucose were added to the basal growth medium $\left(\mathrm{NaNO}_{3}, \mathbf{1 . 5} \mathrm{g}\right.$.; $\mathrm{MgSO}_{4} .7 \mathrm{H}_{2} \mathrm{O}, 0.25 \mathrm{~g}$; $\mathrm{KH}_{2} \mathrm{PO}_{4}, 0.5 \mathrm{~g}$.; $\mathrm{KCl}, 0.25 \mathrm{~g}$; water, $500 \mathrm{ml}$.) to give final concentrations of $0.01 \%(\mathrm{w} / \mathrm{v})$ experiments 1 to 4 or $0.01 \mathrm{M}$ experiments 5 to 6 . Ten ml. lots of media were used. One drop of suspension used as inocula gave zero hour counts (Miles \& Misra, 1938; no. viable particles $\left.\times 10^{-4} / \mathrm{ml}.\right): P$. pullulans, $1 \cdot 4-2.9 ; M$. heteromorpha, 3.5-3.9; M. mutabilis, $14 \cdot 3-17 \cdot 3)$. Growth was for 5 days at $27^{\circ}$ on a shaking machine.

\begin{tabular}{|c|c|c|c|c|}
\hline \multirow[b]{2}{*}{ Expt. no. } & \multirow[b]{2}{*}{ Substrate } & \multicolumn{3}{|c|}{ Number of viable particles $\left(\times 10^{-5}\right) / \mathrm{ml}$. } \\
\hline & & $\boldsymbol{P} \cdot$ pullulans & M. heteromorpha & M. mutabilis \\
\hline \multirow[t]{3}{*}{1} & Control & $0 \cdot 82$ & $57 \cdot 0$ & $3 \cdot 1$ \\
\hline & Glucose & $13 \cdot 0$ & $390 \cdot 0$ & $95 \cdot 0$ \\
\hline & $p$-Hydroxybenzaldehyde & $6 \cdot 4$ & $230 \cdot 0$ & $53 \cdot 0$ \\
\hline \multirow[t]{3}{*}{2} & Control & $1 \cdot 6$ & $28 \cdot 0$ & $6 \cdot 3$ \\
\hline & Glucose & - & 一 & $77 \cdot 0$ \\
\hline & Ferulic acid & $\mathbf{2 5} \cdot \mathbf{0}$ & $120 \cdot 0$ & $77 \cdot 0$ \\
\hline \multirow[t]{3}{*}{$\mathbf{3}$} & Control & $2 \cdot 4$ & $\mathbf{2 8 \cdot 0}$ & $9 \cdot 1$ \\
\hline & Glucose & $14 \cdot 0$ & - & $41 \cdot 0 *$ \\
\hline & Syringaldehyde & $10 \cdot 0$ & $99 \cdot 0$ & $29 \cdot 0^{*}$ \\
\hline \multirow[t]{3}{*}{4} & Control & $2 \cdot 8$ & $41 \cdot 0$ & $7 \cdot 6$ \\
\hline & Glucose & $27 \cdot 0$ & $170 \cdot 0$ & $160 \cdot 0$ \\
\hline & Vanillin & $11 \cdot 0$ & $81 \cdot 0$ & $69 \cdot 0$ \\
\hline \multirow[t]{5}{*}{5} & Control & $3 \cdot 7$ & $40 \cdot 0$ & $9 \cdot 6$ \\
\hline & Glucose & $28 \cdot 0$ & $110 \cdot 0$ & $57 \cdot 0 *$ \\
\hline & Benzoic acid & 0 & 0 & $\mathbf{0}$ \\
\hline & Syringic acid & $0 \cdot 33^{*}$ & $70 \cdot 0$ & $\mathbf{0}$ \\
\hline & Vanillic acid & $29 \cdot 0$ & $120 \cdot 0$ & $18 \cdot 0^{*}$ \\
\hline \multirow[t]{5}{*}{6} & Control & $1 \cdot 8$ & $\mathbf{3 1} \cdot \mathbf{0}$ & $8 \cdot 8$ \\
\hline & Glucose & $610 \cdot 0$ & $2200 \cdot 0$ & $1400 \cdot 0$ \\
\hline & $o$-Hydroxybenzoic acid & 0 & 0 & 0 \\
\hline & $m$-Hydroxybenzoic acid & $\mathbf{0}$ & $390 \cdot 0$ & $\mathbf{0}$ \\
\hline & $p$-Hydroxybenzoic acid & $\mathbf{0}$ & $94 \cdot 0$ & 0 \\
\hline
\end{tabular}

* Many pellets present, decreasing count. 
comparative purposes. In the first four growth experiments the aromatic substrates were $p$-hydroxybenzaldehyde, ferulic acid, syringaldehyde and vanillin. Growth on glucose started immediately, while on the aromatic substrates there was generally little growth after 1 day, the rate of growth increased between 1 and 2 days and reached a maximum after 2 days. It can be seen from Table 1 that the total growth on these aromatic substrates was always considerably greater than that of the controls without added substrate. In the fifth and sixth experiments the aromatic substrates (at $0.01 \mathrm{M}$ ) were benzoic, syringic and vanillic acids and $o-, m$ - and $p$-hydroxybenzoic acids. Estimations of the number of viable particles were made only on the 5th day. The results are given in Table 1. With the exception of benzoic

Table 2. Growth of Pullularia pullulans, Margarinomyces heteromorpha and M. mutabilis on different concentrations of $\mathrm{p}$-hydroxybenzaldehyde, $\mathrm{p}$-hydroxybenzoic acid, vanillin and vanillic acid

Experimental details as in Table 1, but substrates added at concentrations shown and incubation was for 6 days.

\begin{tabular}{|c|c|c|c|c|}
\hline 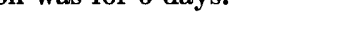 & & centratio & of substr & $(\mathrm{M})$ \\
\hline Substrate & 0.01 & 0.0025 & $0 \cdot 0014$ & 0.001 \\
\hline & & $\boldsymbol{P}$. & llulans & \\
\hline$p$-Hydroxybenzaldehyde & - & - & $(+)$ & $(+$ \\
\hline$p$-Hydrox & $(+)$ & $(+)$ & $(+)$ & \\
\hline Vanillin & - & - & + & \\
\hline Vanillic acid & $+t+t$ & $++(+)$ & ++ & . \\
\hline Control & - & . & . & \\
\hline & & $M$. & utabilis & \\
\hline$p$-Hydroxybenzaldehyde & - & + & ++ & + \\
\hline$p$-Hydroxyben & + & ++ & +++ & + \\
\hline Vanillin & - & $(+)$ & $++(+)$ & $++(t$ \\
\hline Vanillic acid & - & ++ & +++ & ++ \\
\hline Control & $(+)$ & . & - & \\
\hline & & M. he & morpha & \\
\hline$p$-Hydroxybenzaldehyde & - & + & $+(+)$ & $+(+)$ \\
\hline$p$-Hydroxybenzoic acid & +++ & ++ & ++ & + \\
\hline $\begin{array}{l}\text { Vanillin } \\
\text { Vanillic acid }\end{array}$ & $\begin{array}{r}(+) \\
++t\end{array}$ & $\begin{array}{l}(+) \\
++\end{array}$ & $\begin{array}{l}+t \\
t+\end{array}$ & $\begin{array}{l}+ \\
+\end{array}$ \\
\hline Control & $(+)$ & $T$. & & \\
\hline
\end{tabular}

$-=$ no growth; $(+)=$ small amount of growth;,,$+++++++=$ relatively greater amounts of growth.

and $o$-hydroxybenzoic acids all of these substrates supported growth of $M$. heteromorpha, while $\boldsymbol{P}$. pullulans grew only on syringic and vanillic acids and $M$. mutabilis grew only on vanillic acid. A further series of growth experiments used $p$-hydroxybenzaldehyde and vanillin and their corresponding acids at $0.01 \mathrm{M}, 0.025 \mathrm{M}, 0.0014 \mathrm{M}$ and $0.001 \mathrm{M}$, the results are given in Table 2. Counts were not taken, but a visual comparison of growth was made. $\boldsymbol{P}$. pullulans was least, and $\boldsymbol{M}$. heteromorpha most, tolerant of the higher concentrations. $P$. pullulans gave markedly greater growth on vanillic acid than on $p$-hydroxybenzoic acid, which did not occur with the other species. There was a tendency for the acids to support growth at a higher concentration than did their aldehydes. 


\section{DISCUSSION}

The organisms isolated by the soil-enrichment technique used in the present work were all of the same basic morphological types, although some are classified with the yeasts and some with the Hyphomycetes. Trichosporon cutaneum var. multisporum is a yeast, while Phialophora aurantiaca, Margarinomyces heteromorpha, M. mutabilis and Geotrichum candidum are classified in the Hyphomycetes. Pullularia pullulans has been assigned to both groups.

The three isolates which were examined for their ability to grow on the ligninrelated aromatic compounds $p$-hydroxybenzaldehyde, ferulic acid, syringaldehyde and vanillin, were able to utilize them as sole sources of carbon. These compounds were not as readily available as glucose and there was usually a lag of about 2 days before the growth rates reached their maxima, which in each case were similar to the growth rates on glucose. Previous work (Henderson \& Farmer, 1955) revealed the widespread ability of soil microfungi to grow on the above aromatic compounds, while di Menna (1959) found that a number of yeasts could also utilize them. The present studies therefore add to the list of organisms known to attack lignin-related aromatic compounds in soil and emphasize the possible role of micro-organisms in the decomposition of lignin under natural conditions.

The author is indebted to the staff of the Centraalbureau voor Schimmelcultures, Baarn, Netherlands, who identified the isolates. She wishes to acknowledge, also, the technical assistance given by Miss Dorothy Brebner and helpful advice from Dr D. M. Webley.

\section{REFERENCES}

Henderson, M. E. K. \& Farmer, V. C. (1955). Utilization by soil fungi of $p$-hydroxybenzaldehyde, ferulic acid, syringaldehyde and vanillin. J. gen. Microbiol. 12, 37.

Henderson, M. E. K. (1960). Studies on the physiology of lignin decomposition by soil fungi. In The Ecology of Soil Fungi, ed. by D. Parkinson \& J. S. Waid, p. 286. Liverpool: University Press.

Di Menna, M. E. (1959). Some physiological characters of yeasts from soils and allied habitats. J. gen. Microbiol. $20,13$.

Miles, A. A. \& Misra, S. S. (1938). The estimation of the bactericidal power of the blood. J. Hyg., Camb. 38, 732.

Ross, D. J. (1960). Physiological studies of some common fungi from grassland soils. N.Z. J. Sci. Tech. 3, 219.

TurfitT, G. E. (1944). Microbiological agencies in the degradation of steroids (1). The cholesterol decomposing organisms of soils. J. Bact. 47, 487.

Waksman, S. A. (1922). The growth of fungi in the soil. Soil Sci. 14, 153. 